Article

\title{
Benzyl Isothiocyanate Attenuates Inflammasome Activation in Pseudomonas aeruginosa LPS-Stimulated THP-1 Cells and Exerts Regulation through the MAPKs/NF- $\kappa B$ Pathway
}

\author{
Won Sun Park ${ }^{1,+}$, Jeonghan Lee ${ }^{2,+} \mathbb{D}$, Giyoun $\mathrm{Na}^{3}$, SaeGwang Park ${ }^{3}$, Su-Kil Seo ${ }^{3}$, Jung Sik Choi ${ }^{4}$, \\ Won-Kyo Jung ${ }^{5}$ and Il-Whan Choi ${ }^{3, * \mathbb{D}}$
}

check for updates

Citation: Park, W.S.; Lee, J.; Na, G.; Park, S.; Seo, S.-K.; Choi, J.S.; Jung, W.-K.; Choi, I.-W. Benzyl

Isothiocyanate Attenuates

Inflammasome Activation in Pseudomonas aeruginosa LPS-Stimulated THP-1 Cells and Exerts Regulation through the MAPKs/NF-кB Pathway. Int. J. Mol. Sci. 2022, 23, 1228. https://doi.org/ $10.3390 /$ ijms 23031228

Academic Editor: Giuseppe Pugliese

Received: 24 December 2021 Accepted: 20 January 2022

Published: 22 January 2022

Publisher's Note: MDPI stays neutral with regard to jurisdictional claims in published maps and institutional affiliations.

Copyright: (C) 2022 by the authors. Licensee MDPI, Basel, Switzerland. This article is an open access article distributed under the terms and conditions of the Creative Commons Attribution (CC BY) license (https:// creativecommons.org/licenses/by/ $4.0 /)$.
1 Department of Physiology, Kangwon National University School of Medicine, Chuncheon 24341, Korea; parkws@kangwon.ac.kr

2 Department of Anesthesiology and Pain Medicine, Busan Paik Hospital, Inje University, Busan 47392, Korea; ljh646@hanmail.net

3 Department of Microbiology and Immunology, College of Medicine, Inje University, Busan 47392, Korea; gyna80@inje.ac.kr (G.N.); micpsg@inje.ac.kr (S.P.); sseo@inje.ac.kr (S.-K.S.)

4 Department of Internal Medicine, Busan Paik Hospital, Inje University, Busan 47392, Korea; cwj1225@naver.com

5 Department of Biomedical Engineering, Center for Marine-Integrated Biomedical Technology (BK21 Plus), Pukyong National University, Busan 48513, Korea; wkjung@pknu.ac.kr

* Correspondence: cihima@inje.ac.kr

+ These authors contributed equally to this work.

\begin{abstract}
Inflammasomes are a group of intracellular multiprotein platforms that play important roles in immune systems. Benzyl isothiocyanate (BITC) is a constituent of cruciferous plants and has been confirmed to exhibit various biological activities. The modulatory effects of BITC on inflammasomemediated interleukin (IL)-1 $\beta$ expression and its regulatory mechanisms in Pseudomonas aeruginosa (P. aeruginosa) LPS/ATP-stimulated THP-1 cells was investigated. Monocytic THP-1 cells were treated with phorbol myristate acetate (PMA) to induce differentiation into macrophages. Enzymelinked immunosorbent assays (ELISA) were performed to measure the levels of IL- $1 \beta$ produced in P. aeruginosa LPS/ATP-exposed THP-1 cells. Western blotting was performed to examine the BITC modulatory mechanisms in inflammasome-mediated signaling pathways. BITC inhibited IL-1 $\beta$ production in P. aeruginosa LPS/ATP-induced THP-1 cells. BITC also inhibited activation of leucine-rich repeat protein-3 (NLRP3) and caspase-1 in P. aeruginosa LPS/ATP-induced THP-1 cells. Furthermore, we show that mitogen-activated protein kinase (MAPK) and nuclear factor- $\mathrm{B}$ (NF- $\mathrm{kB}$ ) activation in P. aeruginosa LPS was attenuated by BITC. These BITC-mediated modulatory effects on IL-1 $\beta$ production may have therapeutic potential for inflammasome-mediated disorders such as a nasal polyp.
\end{abstract}

Keywords: inflammasomes; benzyl isothiocyanate; interleukin-1 $\beta$; Pseudomonas aeruginosa; THP-1 cells; nuclear factor- $\mathrm{kB}$

\section{Introduction}

Interleukin-1 $\beta$ (IL-1 $\beta)$ is a critical regulator associated with acute and chronic inflammatory responses. IL-1 $\beta$ plays an important role in the pathogenesis of microbial infection and tissue injury, affecting nearly all tissues and organs in the host. Augmented levels of IL-1 $\beta$ have been linked to a broad spectrum of health and disease [1]. Like a double-edged sword, IL-1 $\beta$ is generally essential for normal host defense systems, but failure to control IL- $1 \beta$ destroys tissues and organs. IL- $1 \beta$ is synthesized as a precursor protein (pro-IL-1 $\beta$ ) in the cytosol in response to diverse exogenous or endogenous stimuli [2]. Pro-IL-1 $\beta$ must be cleaved by activated caspase-1, which results in the maturation and secretion of IL-1 $\beta$ in LPS-stimulated cells. Caspase-1 is activated by an assembly of 
intracellular multiprotein complexes called inflammasomes [3]. Inflammasomes contain a nucleotide-binding domain and leucine-rich repeat protein-3 (NLRP3) sensor, an apoptosisassociated speck-like protein containing a caspase-recruitment domain (ASC) adaptor, and a caspase-1 enzyme (pro-caspase-1) [4-6]. It is well known that inflammasomes are activated in macrophages by the immune response to pathogen infections [5]. Generally, the common activation mechanism of inflammasome assembly is pro-caspase- 1 associated with NLRP3 binding to the ASC. Then, pro-caspase- 1 is activated to caspase- 1 and expresses IL-1 $\beta$ as an alarm signal, and IL- $1 \beta$ triggers various mediators, resulting in activation of the immune system, for example, the inflammatory response [7]. Therefore, the activation of inflammasome components represents an important intracellular signaling pathway in inflammatory responses.

Isothiocyanates (ITCs) are phytochemicals abundant in cruciferous vegetables, including broccoli, radishes, cabbage, mustard greens, kale, cauliflower, bok choy, and others that are commonly eaten [8]. ITCs have been used as potent chemopreventive agents with pharmacological activities and possess health advantages and efficacy in the control of various human disorders, such as neurodegenerative diseases, cardiovascular diseases, cancer, and diabetes [9]. ITC groups, such as sulforaphane, moringin, phenethyl isothiocyanate (PITC), allyl isothiocyanate (AITC), phenyl ethyl isothiocyanate (PEITC), and benzyl isothiocyanate (BITC), are derived from the hydrolysis of glucosinolates [10]. Among isothiocyanate groups, BITC (C8H7NS, Figure 1A) exerts antioxidant, anticancer, anti-inflammatory, antimicrobial, and immunomodulatory effects [11-15]. Although some reports have mentioned the anti-inflammatory effect of BITC through inflammasome modulation $[16,17]$, there is no information on the molecular mechanisms of the anti-inflammatory effects of BITCs on macrophages in the nasal polyp environment. A previous study showed that ITC exert antimicrobial activity on Pseudomonas aeruginosa (P. aeruginosa) growth [18]. The present study focused on the BITC-mediated attenuation of P. aeruginosa LPS-stimulated IL-1 $\beta$ production by inhibiting the activation of inflammasome components through the reduction in specific signaling pathways in macrophages. Based on these results, we wanted to know whether BITC can be a therapeutic agent for a wide range of inflammatory disorders, especially nasal polyps.

(A)<smiles>S=C=NCc1ccccc1</smiles>

(B)

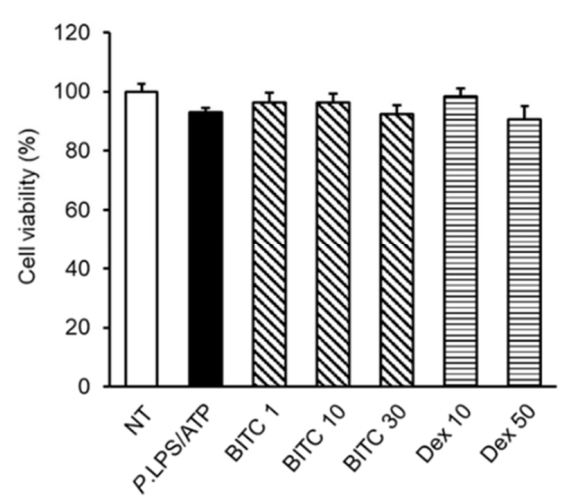

Figure 1. The chemical structure of BITC and the effect of BITC on THP-1 cell viability. (A) Chemical structure of BITC. (B) THP-1 cells were treated with various BITC $(1,10$, and $30 \mu \mathrm{M})$ and Dex $(10$ and $50 \mu \mathrm{M}$ ) concentrations for $24 \mathrm{~h}$. Cell viability was assessed using the CCK- 8 assay, and the results are expressed as the percentage of surviving cells relative to the untreated P. aeruginosa LPS cells. Each value indicates the mean $\pm \mathrm{SD}$ and is representative of results obtained from three independent experiments. NT, non-treated; Dex, dexamethasone; P. LPS, P. aeruginosa LPS.

\section{Results}

\subsection{Effects of BITC on THP-1 Cell Viability}

Initially, we evaluated the viability of THP-1 cells treated with BITC (Figure 1B). Dex $(10$ and $50 \mu \mathrm{M})$ was used as a positive control. Treatment of THP-1 cells with up to $30 \mu \mathrm{M}$ BITC did not affect cell viability. 


\subsection{Effects of BITC on IL-1 1 Expression in P. aeruginosa LPS/ATP-Induced THP-1 Cells}

To evaluate the inhibitory effect of BITC on P. aeruginosa LPS/ATP-stimulated IL-1 $\beta$ expression in THP- 1 cells, IL-1 $\beta$ expression levels in cell culture media were measured. As shown in Figure 2A, treatment with $P$. aeruginosa LPS / ATP markedly increased IL-1 $\beta$ release from THP-1 cells. However, pretreatment with BITC prevented this increase in the levels of IL-1 $\beta$ expression in P. aeruginosa LPS/ ATP-stimulated THP-1 cells. A significantly reduced level of IL- $1 \beta$ was observed at both 10 and $30 \mu \mathrm{M}$ BITC. To secrete IL-1 $\beta$ requires the expression of pro-IL-1 $\beta$ followed by its proteolytic processing by the active caspase- 1 . P. aeruginosa LPS strongly induced pro-IL-1 $\beta$ expression, but BITC treatment significantly decreased the amount of pro-IL-1 $\beta$ in THP-1 cells (Figure 2B).

(A)

(B)
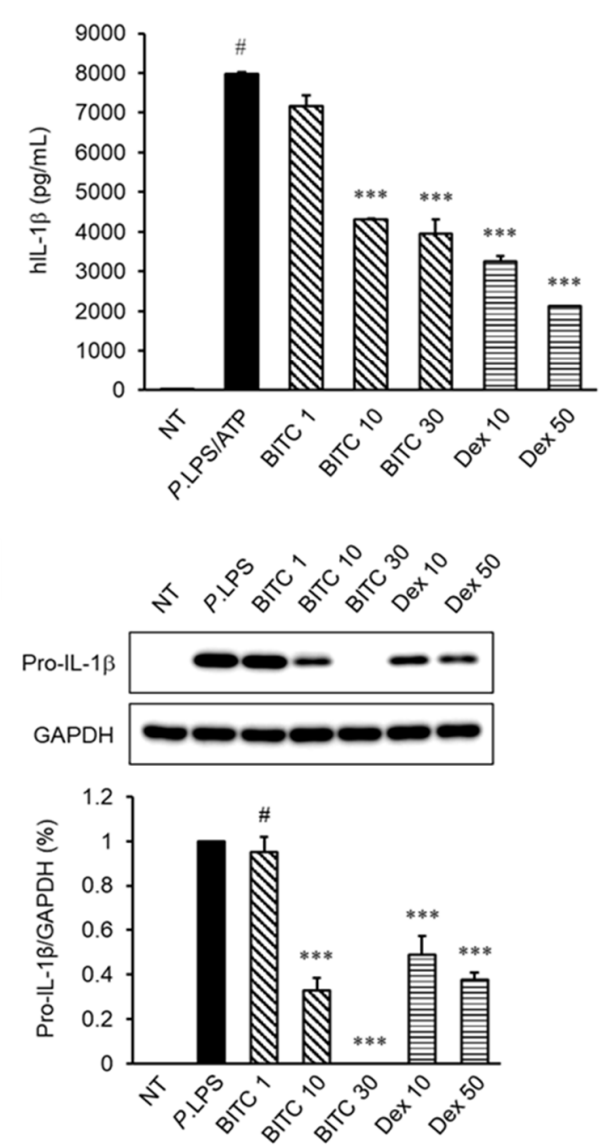

(C)
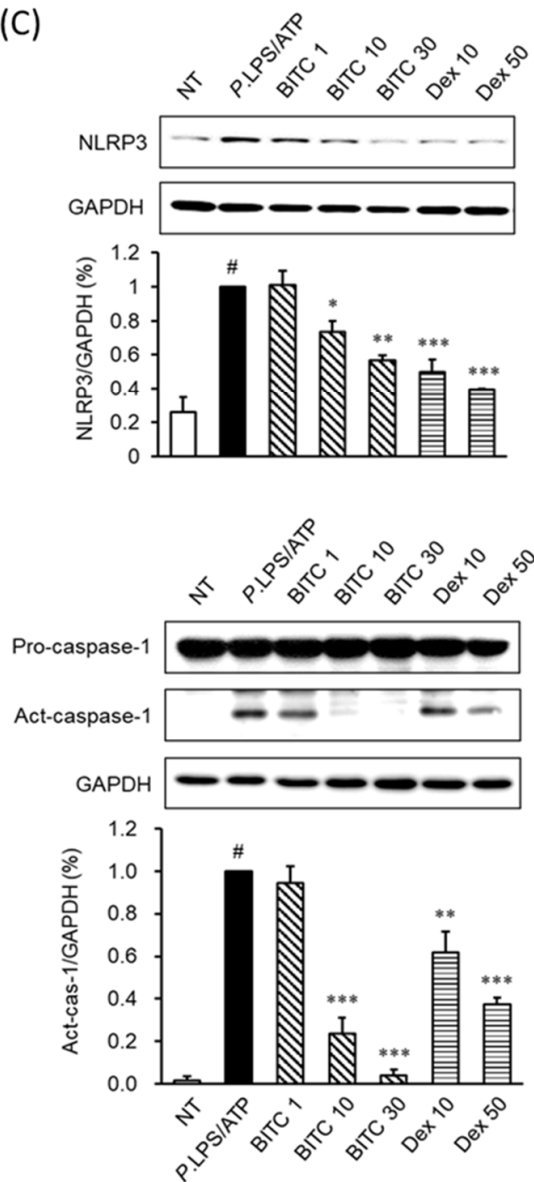

Figure 2. Effects of BITC on IL-1 $\beta$ production and inflammasome activation in P. aeruginosa LPS/ATPstimulated primed THP- 1 cells. The cells were seeded at $1 \times 10^{6}$ cells $/ \mathrm{mL}$ and incubated with various concentrations $(1,10$, and $30 \mu \mathrm{M})$ of BITC for $1 \mathrm{~h}$, followed by P. aeruginosa LPS stimulation $(10 \mu \mathrm{g} / \mathrm{mL})$. The cells were additionally stimulated with $5 \mathrm{mM}$ ATP for $30 \mathrm{~min}$. After stimulation with $P$. aeruginosa LPS, IL-1 $\beta$ production (A, LPS for $24 \mathrm{~h}$ ) and pro-IL-1 $\beta$ expression (B, LPS for $3 \mathrm{~h}$ ) were determined via ELISA and western blotting, respectively. (C) After treatment with LPS/ATP in the presence or absence of BITC for $1 \mathrm{~h}, \mathrm{NLRP} 3$ and caspase-1 protein expression were determined using western blotting. Untreated cells were used as a control. Each value indicates the mean $\pm \mathrm{SD}$ and is representative of results obtained from three independent experiments. $\# p<0.05$ vs. untreated group (NT); ${ }^{*} p<0.05,{ }^{* *} p<0.01,{ }^{* * *} p<0.001$ vs. P. aeruginosa LPS group.

\subsection{Effects of BITC on NLRP3 and Caspase-1 Expression in P. aeruginosa LPS/ATP-Stimulated THP-1 Macrophages}

THP-1 cells were stimulated with P. aeruginosa LPS/ATP in the presence or absence of BITC $(1,10$ and $30 \mu \mathrm{M})$. As shown in Figure $2 \mathrm{C}$, to investigate the effect of BITC on NLRP3 and active caspase-1 expression in LPS/ATP-induced THP-1 cells, we pretreated 
cells with BITC before stimulation with $P$. aeruginosa LPS / ATP. BITC treatment suppressed LPS/ATP-induced NLRP3 production and Act-caspase-1 (subunit p10) activation.

\subsection{Effects of BITC on the Phosphorylation of the MAPK Signaling Pathways in P. aeruginosa} LPS-Stimulated THP-1 Macrophages

To clarify the signaling pathways underlying the attenuation effects of BITC on IL-1 $\beta$ production and inflammasome component activation, we inspected the phosphorylation of mitogen-activated protein kinases (MAPKs). As a result of stimulation with $P$. aeruginosa LPS, phosphorylation of JNK and ERK was increased. The levels of JNK and ERK phosphorylation were highest at 15 and $30 \mathrm{~min}$ after incubation with P. aeruginosa LPS, respectively. However, pretreatment for $1 \mathrm{~h}$ with BITC $(10$ and $30 \mu \mathrm{M})$ attenuated the phosphorylation of JNK and ERK (Figure 3A). To demonstrate whether the ERK and JNK signaling pathways are involved in IL-1 $\beta$ production and inflammasome component activation, THP-1 cells were stimulated with P. aeruginosa LPS/ATP with or without ERK (U 0126)- and JNK (SP 600126)-specific inhibitors. The upregulated production of IL-1 $\beta$ (Figure 3B) and activation of inflammasome components (Figure 3C) were significantly attenuated by U 0126 and SP 600126. This result showed that BITC suppresses IL-1 $\beta$ production and inflammasome activation by inhibiting the ERK and JNK signaling pathways.

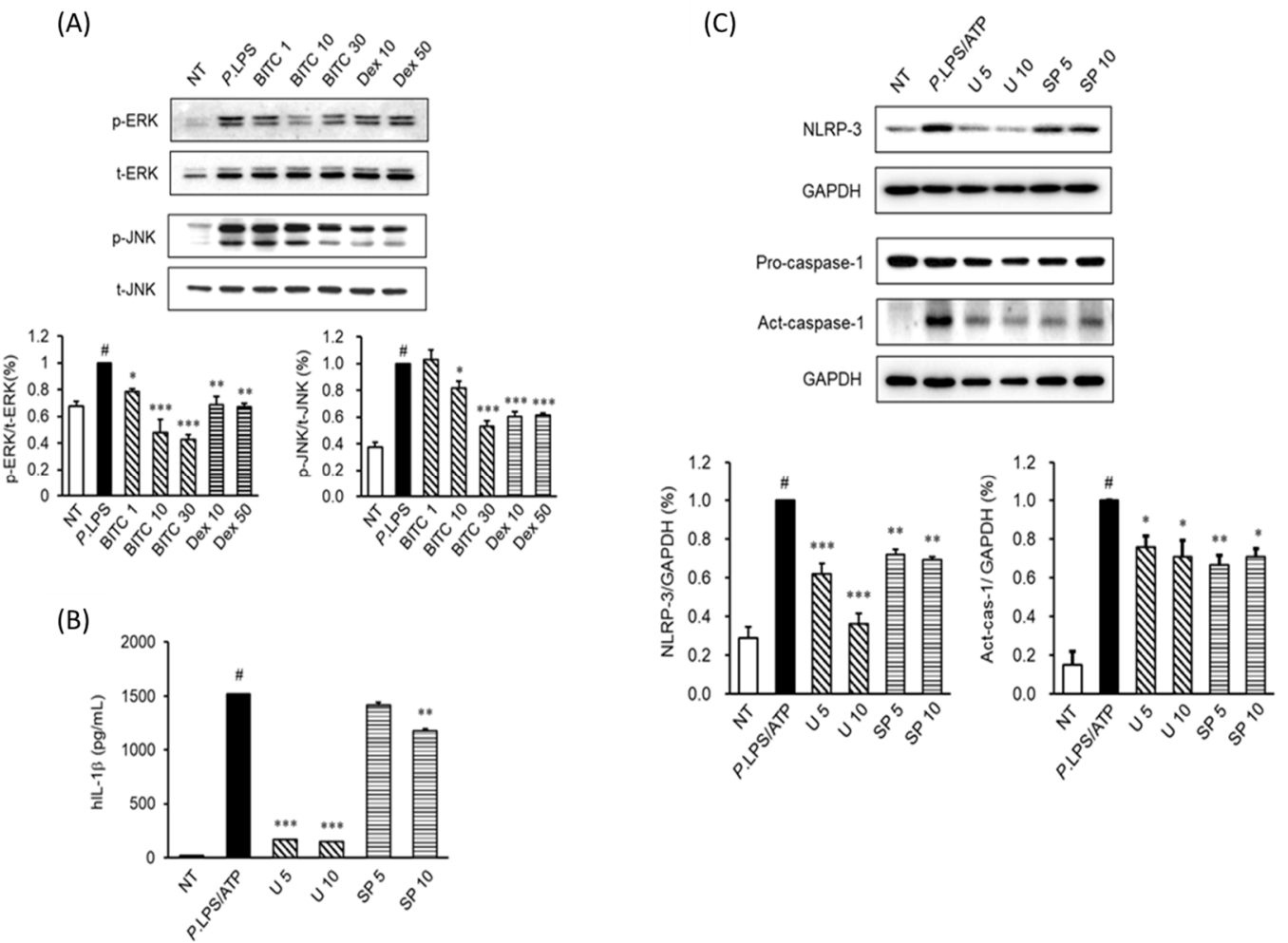

Figure 3. The effects of BITC on inflammasome activation in P. aeruginosa LPS-stimulated THP-1 cells. The cells were seeded at $1 \times 10^{6}$ cells $/ \mathrm{mL}$ and incubated with various BITC concentrations (1, 10, and $30 \mu \mathrm{M})$ for $1 \mathrm{~h}$ prior to P. aeruginosa LPS stimulation $(10 \mu \mathrm{g} / \mathrm{mL})$. (A) After treatment with $P$. aeruginosa LPS for $15 \mathrm{~min}$ and $30 \mathrm{~min}$, the phosphorylated forms of ERK and JNK were determined using western blotting, respectively. (B) After stimulation with P. aeruginosa LPS/ATP for $24 \mathrm{~h}$ in the presence or absence of U 0126 and SP 600126 for $1 \mathrm{~h}$, IL-1 $\beta$ production by THP-1 cells was determined via ELISA. (C) After treatment with LPS/ATP in the presence or absence of U 0126 (5 and $10 \mu \mathrm{M})$ and SP 600126 (5 and $10 \mu \mathrm{M}$ ) for $1 \mathrm{~h}$, NLRP3 and caspase-1 protein expression were determined using western blotting. GAPDH was used as an internal control for the western blot analyses. Each value indicates the mean $\pm \mathrm{SD}$ and is representative of results obtained from three independent experiments. \# $p<0.05$ vs. untreated group; ${ }^{*} p<0.05,{ }^{* *} p<0.01$ and ${ }^{* * *} p<0.001$ vs. P. aeruginosa LPS group. NT, untreated group; U, U 0126; SP, SP 600126. 


\subsection{The Effects of BITC on NF- $\kappa B$ Activation in LPS-Stimulated THP-1 Macrophages}

We investigated whether BITC attenuates NF- $\mathrm{KB}$ nuclear translocation. Western blot images revealed that LPS stimulation of THP- 1 cells strongly induces NF- $\mathrm{kB}$ p65 nuclear localization and I $\kappa \mathrm{B} \alpha$ phosphorylation in the cytosol. However, BITC treatment attenuated LPS-induced NF- $\kappa B$ p65 nuclear localization. Additionally, the phosphorylation of IкB $\alpha$ in the cytosol was significantly inhibited by the BITC treatment of THP-1 cells (Figure 4A). Next, to verify whether the NF- $\kappa B$ p 65 signaling pathway is involved in IL-1 $\beta$ production and inflammasome component activation, THP-1 cells were stimulated with P. aeruginosa LPS/ATP with or without NF- $\mathrm{kB}$ inhibitors (Bay 11-7082 and parthenolide). The upregulated production of IL-1 $\beta$ (Figure $4 \mathrm{~B}$ ) and activation of the inflammasome components NLRP-3 and caspase-1 (Figure 4C) were significantly attenuated by NF- $\kappa B$ inhibitors. These results suggest that attenuation of NF- $\mathrm{KB}$ activation by BITC may be the signaling pathway responsible for the inhibition of IL- $1 \beta$ production and inflammasome activation in $P$. aeruginosa LPS/ATP-stimulated THP-1 cells.

(A)
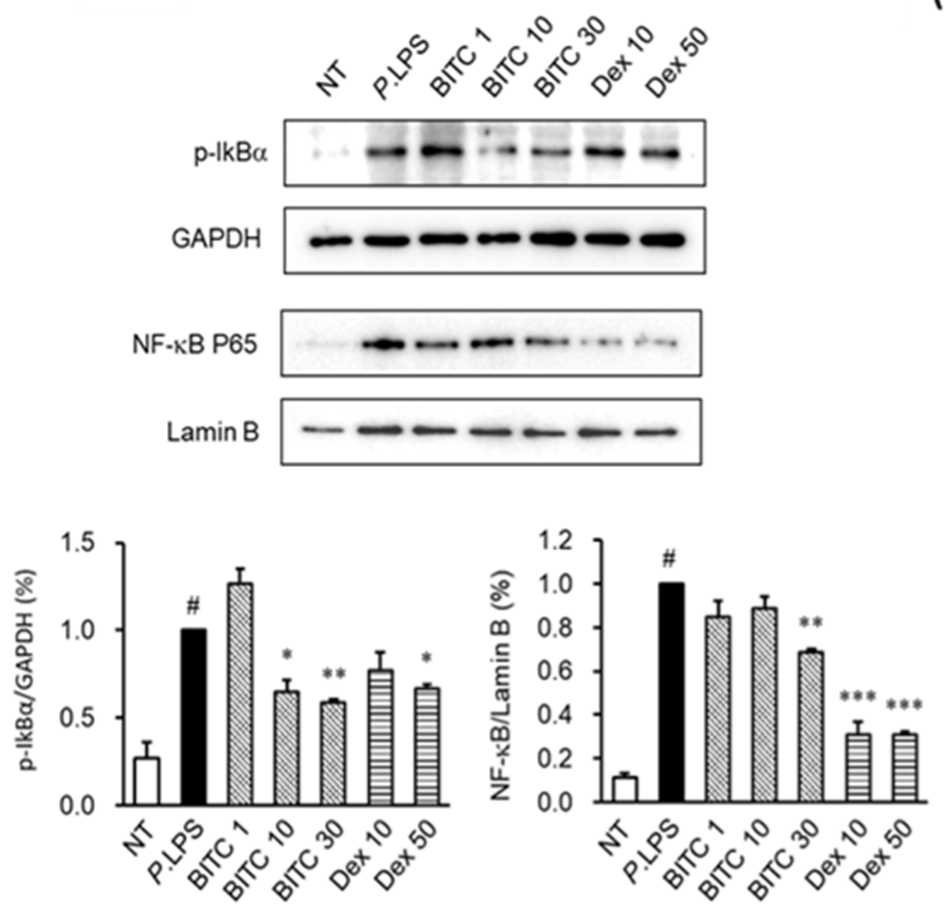

(B)

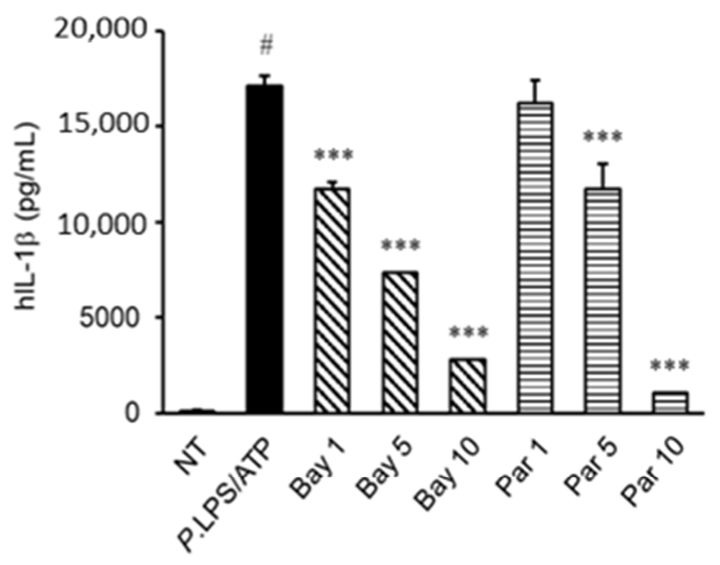

Figure 4. Cont. 
(C)
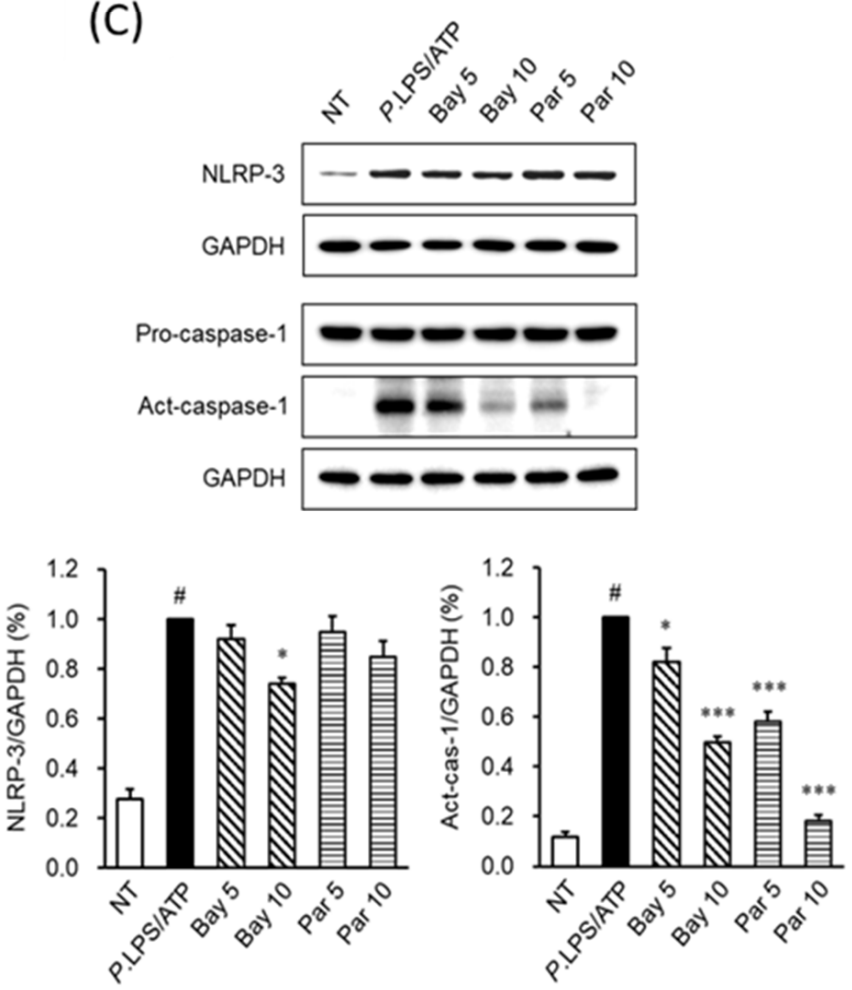

Figure 4. The effect of BITC on NF-kB activation in P. aeruginosa LPS-stimulated THP-1 cells. (A) The cells were pretreated with BITC $(1,10$, and $30 \mu \mathrm{M})$ for $1 \mathrm{~h}$ and then stimulated with $P$. aeruginosa LPS for $1 \mathrm{~h}$. Cytosol protein extracts were prepared as described in the materials and methods and evaluated for phosphorylation of $\operatorname{IkB} \alpha$ using western blot analyses. Nuclear protein extracts were prepared and analyzed for NF- $\mathrm{kB}$ nuclear translocation using western blot analyses. (B) After stimulation with P. aeruginosa LPS/ATP for $24 \mathrm{~h}$ in the presence or absence of Bay 11-7082 (1, 5, and $10 \mu \mathrm{M})$ and parthenolide $(1,5$, and $10 \mu \mathrm{M})$ for $1 \mathrm{~h}$, IL-1 $\beta$ production by THP- 1 cells was determined via ELISA. (C) After treatment with LPS/ATP in the presence or absence of Bay 11-7082 and parthenolide for $1 \mathrm{~h}$, NLRP3 (LPS for $3 \mathrm{~h}$ ) and caspase-1 (LPS for $1 \mathrm{~h}$ ) protein expression were determined using western blotting. GAPDH was used as an internal control for the western blot analyses. Each value indicates the mean $\pm \mathrm{SD}$ and is representative of results obtained from three independent experiments. \# $p<0.05$ vs. untreated group; ${ }^{*} p<0.05$, ${ }^{* *} p<0.01$ and ${ }^{* * *} p<0.001$ vs. P. aeruginosa LPS group. NT, untreated group; Bay, Bay 11-7082; Par, parthenolide.

\section{Discussion}

The final objectives of this research were to verify whether IL-1 $\beta$ produced by endotoxinstimulated activation of inflammasomes induces fibrosis and to reveal the reaction mechanism in the growth of nasal polyps (NPs). NPs are a chronic disease of the nose and sinuses with nasal obstruction, runny nose, smell and taste loss, headache, and a high recurrence rate after medical or surgical treatment, often leading to substantial impairment of the quality of life of the patient [19]. IL-1 $\beta$ is expressed in NPs, and P. aeruginosa is a common culture isolate in chronic rhinosinusitis (CRS) [20]. In a previous study, NLRP3 was highly expressed in NPs from subjects with CRSwNP [21]. To understand whether fibrosis occurs during NP growth due to IL-1 $\beta$, first, the production of inflammasome-mediated IL-1 $\beta$ by P. aeruginosa LPS/ATP stimulation in macrophages was investigated. Additionally, work was carried out to obtain a substance capable of inhibiting the production of IL-1 $\beta$ via attenuation of inflammasome activation.

NPs are infiltrated by various inflammatory and immune cells, such as plasma cells, lymphocytes, mast cells, eosinophils, neutrophils, and macrophages [22]. Among these cells, macrophages were identified in both the stroma and the epithelium lining the NPs [23]. Macrophages are innate immune effector cells of the innate immune system that play an 
important role in the recognition and elimination of a foreign pathogen. The primary cytokines produced by macrophages are IL- $1 \beta$, IL- 6 , IL- 8 , IL-33, and TNF- $\alpha$. THP- 1 cells in the monocyte state can be differentiated into macrophage-like cells by induction of PMA. Various macrophage phenotypic intermediates can develop from THP-1 cells during PMA stimulation, showing similarities to primary monocytes and macrophages in terms of morphological and functional properties, including differentiation markers [24]. Therefore, THP-1 cells have been widely used as a suitable in vitro model of human macrophages in mechanistic studies of external stimuli. Macrophages are used as model cell lines to research inflammasome activation for therapeutic and/or mechanistic studies [25]. The upper airways, including the nasopharynx and paranasal sinuses, have been shown to be a silent reservoir for P. aeruginosa [26]. Additionally, P. aeruginosa was significantly more common in noneosinophilic CRSwNP patients in a sample of Korean adults [27]. Therefore, we used a model that stimulates macrophages with $P$. aeruginosa LPS in this study.

LPS produces IL-1 $\beta$ in an inflammasome-mediated manner in THP-1 cells [28,29]. As expected, the production of IL- $1 \beta$ was significantly increased by P. aeruginosa LPS stimulation in our experimental system. However, the increased IL-1 $\beta$ was inhibited in a dose-dependent manner by treatment with 10 and $30 \mu \mathrm{M}$ BITC without cytotoxicity (Figure 2A). This result suggests that BITC inhibits the IL- $1 \beta$ production by suppressing the $P$. aeruginosa LPS-induced signaling pathways. Several studies have reported that LPS stimulates IL-1 $\beta$ production through the activation of inflammasomes $[30,31]$. In this regard, we investigated whether BITC inhibits the activation of inflammasomes such as NLRP3 and caspase- 1 in the cytosol. As shown in Figure 2B,C, treatment with BITC significantly attenuated the pro-IL-1 $\beta$ and inflammasome (NLRP3 and active caspase-1) activation in a dose-dependent manner and hence may be beneficial in inflammasome-mediated anti-inflammatory response.

Next, we investigated the signaling mechanism of inflammasome activation in differentiated THP-1 macrophages. It is well known that in macrophages, P. aeruginosa LPS stimulates MAPKs, including ERK, p38, and JNK and NF-kB pathway activation to upregulate IL-1 $\beta$ production through inflammasome activation [32-34]. As shown in Figure 3A, treatment with BITC ameliorated this phosphorylation of ERK and JNK. To verify whether $P$. aeruginosa LPS induces IL-1 $\beta$ production and inflammasome activation through the MAPK signaling pathway, we used specific inhibitors of MAPKs under $P$. aeruginosa LPS stimulation. As expected, our results showed that specific inhibitors of ERK and JNK inhibited IL-1 $\beta$ production (Figure 3B) and inflammasome activation (Figure 3C) in LPS/ATP-stimulated THP-1 cells, suggesting that BITC may be useful for IL-1 $\beta$ production and inflammasome activation through the modulation of ERK and JNK signal activation. Inflammasome activation has been widely implicated in NF- $\kappa$ B signaling [33,35]. Therefore, we examined NF-kB signaling in P. aeruginosa LPS-stimulated THP-1 cells. We used western blot analysis to explore NF- $\kappa B$ activation status. When cells are stimulated with LPS, IKB $\alpha$ is phosphorylated and then ubiquitinated, leading to its degradation. In our results, P. aeruginosa LPS significantly induced IKB $\alpha$ phosphorylation in the cytosol, but BITC treatment blocked I $\kappa \mathrm{B} \alpha$ phosphorylation. In addition, NF- $\kappa \mathrm{B}$ was translocated to nuclei by $P$. aeruginosa LPS in THP-1 cells. However, NF-kB nuclear translocation induced by $P$. aeruginosa LPS was attenuated by BITC. To verify whether LPS induces IL- $1 \beta$ production and inflammasome activation through NF- $\kappa B$ activation, we used specific inhibitors of NF-KB (Bay 11-7082 and parthenolide) under P. aeruginosa LPS stimulation. Our results showed that specific inhibitors of NF- $\kappa$ B inhibited IL-1 $\beta$ production and inflammasome activation, suggesting that BITC may be useful for IL-1 $\beta$ production and inflammasome activation through the regulation of NF-kB activation. Together with our mechanistic results, the results indicate that BITC attenuated P. aeruginosa LPS-stimulated IL- $1 \beta$ production via inflammasome activation by suppressing ERK, JNK, and NF- $\mathrm{BB}$ signaling in vitro. Our results are consistent with those of previous publications, showing that BITC exerts a pharmacological effect, which is probably mediated via the inhibition of MAPKs and NF- $\kappa$ B signaling $[13,36]$. 


\section{Materials and Methods}

\subsection{Reagents}

We obtained LPS derived from P. aeruginosa, dexamethasone (Dex), U 0126, phorbol 12-myristate 13-acetate (PMA), Adenosine triphosphate (ATP), and BITC from SigmaAldrich (St. Louis, MO, USA). SP 600126 was obtained from Enzo Life Sciences, Inc. (Farmingdale, NY, USA). BAY 11-7082 and parthenolide were obtained from Santa Cruz Biotechnology Inc. Cell Counting Kit-8 (CCK-8) was obtained from Dojindo Laboratories (Kumamoto, Japan). Antibodies against caspase- 1 and pro-IL-1 $\beta$ were obtained from Abcam Inc. (Cambridge, MA, USA). Anti-NF-kB p65 antibodies were purchased from eBioscience (San Diego, CA, USA). Anti-NLRP-3 antibodies were obtained from AdipoGen (San Diego, CA, USA). Antibodies against extracellular signal-related kinase (ERK), phospho (p)-ERK, c-Jun N-terminal kinase (JNK), p-JNK, and p-IkB- $\alpha$ were obtained from Cell Signaling Technology, Inc. (Danvers, MA, USA). Anti-Lamin B antibodies were obtained from Santa Cruz Biotechnology (Santa Cruz, CA, USA). Goat anti-rabbit IgG-horseradish peroxidase was obtained from A-Frontier (Seoul, Korea). The CellTiter-Glo ${ }^{\circledR}$ Luminescent assay was obtained from Promega (Madison, WI, USA).

\subsection{Cell Culture and Differentiation}

The THP-1 human leukemia cell line was purchased from the American Type Culture Collection (Manassas, VA, USA). Cells were cultured in RPMI-1640 medium with 10\% FBS THP-1 cells were differentiated using $50 \mathrm{nM}$ PMA and incubated. After treatment with PMA for $48 \mathrm{~h}$, fresh medium was added for an additional $24 \mathrm{~h}$ before P. aeruginosa LPS treatment. Cells were checked under a light microscope for evidence of differentiation.

\subsection{Drug Treatment and Cell Viability Assay}

Cells were seeded at $1 \times 106$ cells $/ \mathrm{mL}$ and treated with $10 \mu \mathrm{g} / \mathrm{mL}$ P. aeruginosa LPS + $5 \mathrm{mM}$ ATP (LPS/ATP) after treatment with the indicated concentrations of BITC or Dex for $1 \mathrm{~h}$ in PMA-free conditions. After treatment with P. aeruginosa LPS/ATP for $24 \mathrm{~h}$, cellular viability was assessed using the CCK-8 method. We added CCK-8 to each well and incubated it at $37^{\circ} \mathrm{C}$ for $1 \mathrm{~h}$, followed by an analysis at $450 \mathrm{~nm}$ using a microplate reader (SpectraMax M2e, Molecular Devices, Sunnyvale, CA, USA).

\subsection{Enzyme-Linked Immunosorbent Assay (ELISA)}

After treatment with P. aeruginosa LPS/ATP with or without BITC or specific inhibitors in PMA-differentiated THP-1 cells, the level of IL-1 $\beta$ production was measured using an ELISA kit (R\&D Systems, Minneapolis, MN, USA). The ELISA results were quantified using an ELISA plate reader (SpectraMax M2e) at $450 \mathrm{~nm}$ with a correction of $540 \mathrm{~nm}$.

\subsection{Western Blot Analysis}

PMA-differentiated THP-1 cells were stimulated with P. aeruginosa LPS with or without pretreatment with BITC or specific inhibitors. Proteins were collected using a NE-PER nuclear and cytoplasmic extraction reagent kit (Pierce, Rockford, IL, USA). Equal quantities of protein were separated on $10 \%$ SDS-polyacrylamide minigels and transferred to nitrocellulose membranes. Incubation with the appropriate primary antibodies was performed overnight at $4{ }^{\circ} \mathrm{C}$. Then, the membranes were incubated for $1 \mathrm{~h}$ at room temperature with a secondary antibody (goat anti-rabbit IgG and goat anti-mouse IgG) conjugated to horseradish peroxidase. Following three washes in Tris-buffered saline Tween-20 (TBST 20), the immunoreactive bands were visualized using an ECL detection system (Pierce, Rockford, IL, USA). Quantitative data were obtained by densitometry analysis using Multi Gauge version 2.2 software (Fuji Film, Tokyo, Japan).

\subsection{Statistical Analysis}

Data are presented as the mean \pm SD. All statistical analyses were performed using GraphPad Prism software 5.0 (GraphPad Software Inc., La Jolla, CA, USA). Comparisons 
between groups were performed by Dunnett's multiple range tests. Values of $p<0.05$ were considered to be statistically significant.

\section{Conclusions}

In this study, our data demonstrated that BITC treatment suppresses IL- $1 \beta$ production via inhibition of inflammasome activation in P. aeruginosa LPS-stimulated THP-1 macrophages. In addition, these inhibitory activities of BITC were mediated through the modulation of both the MAPK and NF- $\mathrm{KB}$ signaling pathways. Thus, BITC may be a useful novel therapy for LPS-associated inflammatory pathological conditions, including nasal polyps (NP), by targeting inflammasome-mediated IL- $1 \beta$ production signaling pathways. In the next study, we will conduct further investigation to determine whether BITC suppresses IL-1 $\beta$-induced fibrosis in nasal-polyp-derived fibroblasts (NPDFs) via the excessive accumulation of cellular sources of extracellular matrix (ECM) proteins, which are hallmarks of fibrosis, such as collagen- 1 and fibronectin, that could be involved in the growth of NPs. Then, using BITC, we plan to conduct ex vivo experiments on the effect of NP growth. Therefore, fibrosis is triggered by inflammasome-mediated IL-1 $\beta$ expression activated after $P$. aeruginosa LPS stimulation, and we plan to verify the efficacy of BITC for regulating NP growth.

Author Contributions: Conceptualization, W.S.P., J.L. and I.-W.C.; methodology and software, G.N. and J.S.C.; validation, formal analysis, and investigation, S.P., S.-K.S. and W.-K.J.; writing-original draft preparation, I.-W.C.; writing - review and editing, project administration, and funding acquisition, W.S.P. and I.-W.C. All authors have read and agreed to the published version of the manuscript.

Funding: This research was supported by Inje University Research Grant 2017.

Institutional Review Board Statement: Not applicable.

Informed Consent Statement: Not applicable.

Data Availability Statement: Not applicable.

Conflicts of Interest: The authors declare no conflict of interest.

\section{References}

1. Dinarello, C.A. Overview of the IL-1 family in innate inflammation and acquired immunity. Immunol. Rev. 2018, 281, 8-27. [CrossRef] [PubMed]

2. Netea, M.G.; Simon, A.; van de Veerdonk, F.; Kullberg, B.J.; Van der Meer, J.W.; Joosten, L.A. IL-1 $\beta$ Processing in Host Defense: Beyond the Inflammasomes. PloS Pathog. 2010, 6, e1000661. [CrossRef] [PubMed]

3. Franchi, L.; Eigenbrod, T.; Muñoz-Planillo, R.; Nuñezl, G. The Inflammasome: A Caspase-1 Activation Platform Regulating Immune Responses and Disease Pathogenesis. Nat. Immunol. 2009, 10, 241-247. [CrossRef]

4. Latz, E.; Xiao, T.S.; Stutz, A. Activation and regulation of the inflammasomes. Nat. Rev. Immunol. 2013, 13, 397-411. [CrossRef] [PubMed]

5. Seok, J.K.; Kang, H.C.; Cho, Y.-Y.; Lee, H.S.; Lee, J.Y. Therapeutic regulation of the NLRP3 inflammasome in chronic inflammatory diseases. Arch. Pharm. Res. 2021, 44, 16-35. [CrossRef]

6. Cordaro, M.; Salinaro, A.T.; Siracusa, R.; D’Amico, R.; Impellizzeri, D.; Scuto, M.; Ontario, M.L.; Cuzzocrea, S.; Paola, R.D.; Fusco, R.; et al. Key Mechanisms and Potential Implications of Hericium erinaceus in NLRP3 Inflammasome Activation by Reactive Oxygen Species during Alzheimer's Disease. Antioxidants 2021, 10, 1664. [CrossRef]

7. Wang, X.; Eagen, W.J.; Lee, J.C. Orchestration of human macrophage NLRP3 inflammasome activation by Staphylococcus aureus extracellular vesicles. Proc. Natl. Acad. Sci. USA 2020, 117, 3174-3184. [CrossRef]

8. Zhang, Z.; Bergan, R.; Shannon, J.; Slatore, C.G.; Bobe, G.; Takata, Y. The Role of Cruciferous Vegetables and Isothiocyanates for Lung Cancer Prevention: Current Status, Challenges, and Future Research Directions. Mol. Nutr. Food Res. 2018, 62, e1700936. [CrossRef]

9. Kala, C.; Ali, S.S.; Ahmad, N.; Gilani, S.J.; Khan, N.A. Isothiocyanates: A Review. Res. J. Pharmacog. 2018, 5, 71-89. [CrossRef]

10. Romeo, L.; Iori, R.; Rollin, P.; Bramanti, P.; Mazzon, E. Isothiocyanates: An Overview of Their Antimicrobial Activity against Human Infections. Molecules 2018, 23, 624. [CrossRef]

11. Huang, S.H.; Wu, L.W.; Huang, A.C.; Yu, C.C.; Lien, J.C.; Huang, Y.P.; Yang, J.S.; Yang, J.H.; Hsiao, Y.P.; Wood, W.G.; et al. Benzyl isothiocyanate (BITC) induces G2/M phase arrest and apoptosis in human melanoma A375.S2 cells through reactive oxygen species (ROS) and both mitochondria-dependent and death receptor-mediated multiple signaling pathways. J. Agric. Food Chem. 2012, 60, 665-675. [CrossRef] [PubMed] 
12. Xiao, D.; Bommareddy, A.; Kim, S.; Sehrawat, A.; Hahm, E.; Singh, S.V. Benzyl Isothiocyanate Causes FoxO1-Mediated Autophagic Death in Human Breast Cancer Cells. PLoS ONE 2012, 7, 3. [CrossRef] [PubMed]

13. Lee, Y.M.; Seon, M.R.; Cho, H.J.; Kim, J.; Park, J.H. Benzyl isothiocyanate exhibits anti-inflammatory effects in murine macrophages and in mouse skin. J. Mol. Med. 2009, 87, 1251-1261. [CrossRef] [PubMed]

14. Dufour, V.; Alazzam, B.; Ermel, G.; Thepaut, M.; Rossero, A.; Tresse, O.; Baysse, C. Antimicrobial activities of isothiocyanates against Campylobacter jejuni isolates. Front. Cell Infect. Microbiol. 2012, 2, 53. [CrossRef]

15. Mastuo, T.; Miyata, Y.; Yuno, T.; Mukae, Y.; Otsubo, A.; Mitsunari, K.; Ohba, K.; Sakai, H. Molecular Mechanisms of the Anti-Cancer Effects of Isothiocyanates from Cruciferous Vegetables in Bladder Cancer. Molecules 2020, 25, 575. [CrossRef]

16. Chen, H.W.; Yen, C.C.; Kuo, L.L.; Lo, C.W.; Huang, C.S.; Chen, C.C.; Lii, C.K. Benzyl isothiocyanate ameliorates highfat/cholesterol/cholic acid diet-induced nonalcoholic steatohepatitis through inhibiting cholesterol crystal-activated NLRP3 inflammasome in Kupffer cells. Toxicol. Appl. Pharmacol. 2020, 393, 114941. [CrossRef]

17. Lee, C.M.; Lee, D.S.; Jung, W.K.; Yoo, J.S.; Yim, M.J.; Choi, Y.H.; Park, S.; Seo, S.K.; Choi, J.S.; Lee, Y.M.; et al. Benzyl isothiocyanate inhibits inflammasome activation in E. coli LPS-stimulated BV2 cells. Int. J. Mol. Med. 2016, 38, 912-918. [CrossRef]

18. Borges, A.; Ferreira, C.; Saavedra, M.J.; Simões, L.C.; Simões, M. Antibacterial activity and mode of action of selected glucosinolate hydrolysis products against bacterial pathogens. J. Food Sci. Technol. 2015, 52, 4737-4748. [CrossRef]

19. Park, J.; Choi, G.; Yim, M.J.; Lee, J.M.; Yoo, J.S.; Park, W.S.; Park, S.K.; Park, S.; Seo, S.K.; Kim, T.G.; et al. Effect of phlorotannins on myofibroblast differentiation and ECM protein expression in transforming growth factor $\beta 1$-induced nasal polyp-derived fibroblasts. Int. J. Mol. Med. 2018, 42, 2213-2220. [CrossRef]

20. Zhang, Z.; Adappa, N.D.; Doghramji, L.J.; Chiu, A.G.; Cohen, N.A.; Palmer, J.N. Different clinical factors associated with Staphylococcus aureus and Pseudomonas aeruginosa in chronic rhinosinusitis. Int. Forum Allergy Rhinol. 2015, 5, 724-733. [CrossRef]

21. Wei, Y.; Zhang, J.; Wu, X.; Sun, W.; Wei, F.; Liu, W.; Lu, T.; Ji, W.; Li, H.; Wen, W. Activated pyrin domain containing 3 (NLRP3) inflammasome in neutrophilic chronic rhinosinusitis with nasal polyps (CRSwNP). J. Allergy Clin. Immunol. 2020, 145, 1002-1005.e16. [CrossRef] [PubMed]

22. Polzehl, D.; Moeller, P.; Riechelmann, H.; Perner, S. Distinct features of chronic rhinosinusitis with and without nasal polyps. Alergy 2006, 61, 1275-1279. [CrossRef] [PubMed]

23. Dutsch-Wicherek, M.; Tomaszewska, R.; Lazar, A.; Strek, P.; Wicherek, Ł.; Piekutowski, K.; Jóźwicki, W. The evaluation of metallothionein expression in nasal polyps with respect to immune cell presence and activity. BMC Immunol. 2010, 11, 10. [CrossRef]

24. Tregei, S.; Bauler, T.J.; Malik-Kale, P.; Steele-Mortimer, O. The phorbol 12-myristate-13-acetate differentiation protocol is critical to the interaction of THP-1 macrophages with Salmonella typhimurium. PLoS ONE 2018, 13, e0193601. [CrossRef]

25. Zito, G.; Buscetta, M.; Cimino, M.; Dino, P.; Bucchieri, F.; Cipollina, C. Cellular Models and Assays to Study NLRP3 Inflammasome Biology. Int. J. Mol. Sci. 2020, 21, 4294. [CrossRef]

26. Fothergill, J.L.; Neill, D.R.; Loman, N.; Winstanley, C.; Kadioglu, A. Pseudomonas aeruginosa adaptation in the nasopharyngeal reservoir leads to migration and persistence in the lungs. Nat. Commun. 2014, 5, 4780. [CrossRef]

27. Kim, D.; Assiri, A.M.; Kim, J.H. Recent Trends in Bacteriology of Adult Patients with Chronic Rhinosinusitis. J. Clin. Med. 2019, 8, 1889. [CrossRef]

28. Wang, H.; Mao, L.; Meng, G. The NLRP3 Inflammasome activation in human or mouse cells, sensitivity causes puzzle. Protein Cell 2013, 4, 565-568. [CrossRef]

29. Yang, Q.; Liu, Q.; Lv, H.; Wang, F.; Liu, R.; Zeng, N. Effect of pulegone on the NLPR3 inflammasome during inflammatory activation of THP-1 cells. Exp. Ther. Med. 2020, 19, 1304-1312. [CrossRef]

30. He, Y.; Hara, H.; Núñez, G. Mechanism and Regulation of NLRP3 Inflammasome Activation. Trends Biochem. Sci. 2016, 41, 1012-1021. [CrossRef]

31. Wu, L.; Zhou, C.; Wu, J.; Chen, S.; Tian, Z.; Du, Q. Corticosterone Inhibits LPS-Induced NLRP3 Inflammasome Priming in Macrophages by Suppressing Xanthine Oxidase. Mediat. Inflamm. 2020, 2020, 6959741. [CrossRef] [PubMed]

32. Chen, X.; Wang, N.; Zhu, Y.; Lu, Y.; Liu, X.; Zheng, J. The Antimalarial Chloroquine Suppresses LPS-Induced NLRP3 Inflammasome Activation and Confers Protection against Murine Endotoxic Shock. Mediat. Inflamm. 2017, 2017, 6543237. [CrossRef] [PubMed]

33. Hu, Y.; Zhou, Q.; Liu, T.; Liu, Z. Coixol Suppresses NF-кB, MAPK Pathways and NLRP3 Inflammasome Activation in Lipopolysaccharide-Induced RAW 264.7 Cells. Molecules 2020, 25, 894. [CrossRef] [PubMed]

34. Liu, T.; Zhang, L.; Joo, D.; Sun, S. NF-kB signaling in inflammation. Signal Transduct. Target. Ther. 2017, 2, 17023. [CrossRef]

35. Fayyaz, S.; Haasken, S.; Cassel, S.L. Mechanism of NLRP3 inflammasome activation. Ann. N. Y. Acad. Sci. 2014, 1319, 82-95. [CrossRef]

36. Ho, C.C.; Lai, K.C.; Hsu, S.C.; Kuo, C.L.; Ma, C.Y.; Lin, M.L.; Yang, J.S.; Chung, J.G. Benzyl isothiocyanate (BITC) inhibits migration and invasion of human gastric cancer AGS cells via suppressing ERK signal pathways. Hum. Exp. Toxicol. 2011, 30, 296-306. [CrossRef] 